Journal of Mechanical Engineering and Sciences (JMES)

ISSN (Print): 2289-4659; e-ISSN: 2231-8380; Volume 1, pp. 25-36, December 2011

(C) Universiti Malaysia Pahang, Pekan, Pahang, Malaysia

DOI: http://dx.doi.org/10.15282/jmes.1.2011.3.0003

\title{
A STUDY ON THE POTENTIAL OF COST AND ENERGY - A SURVEY AT PLAYFORD BUILDING, UNIVERSITY OF SOUTH AUSTRALIA
}

\author{
J. Ramli ${ }^{1}$, Y. Nor Imrah ${ }^{1}$, A.R. Jeefferie ${ }^{2}$ and M.M. Mahat ${ }^{3}$ \\ ${ }^{1}$ Faculty of Mechanical Engineering, Universiti Malaysia Pahang \\ 26600, Kuantan, Pahang Darul Makmur, Malaysia \\ Email: ramli@ump.edu.my \\ ${ }^{2}$ Faculty of Manufacturing Engineering, Universiti Teknikal Malaysia Melaka \\ Hang Tuah Jaya, 76100, Durian Tunggal, Melaka, Malaysia \\ ${ }^{3}$ Faculty of Applied Sciences, Universiti Teknologi MARA, 40450, Shah Alam \\ Selangor Darul Ehsan, Malaysia
}

\begin{abstract}
This report summarizes a study on energy consumption of a building, and offers recommendations to reduce the cost of energy usage. Playford building, of the University of South Australia, has been chosen as the study example for completing this survey. The study uses three phases of workflow: an audit of historical energy consumption data, a screening survey, and a detailed investigation and analysis of the building itself. One year of past data have been retrieved and analyzed. Causes of energy wastage and areas with potential for energy savings have been identified by walk-through survey across two levels of the building, chosen to represent the entire building. Possible ways of reducing energy consumption have been recommended. An estimation of the energy savings, following implementation of the recommendations, has been calculated including costs that would be incurred. It was found that for six recommendations, an estimated $20.4 \%$ of energy could be saved relative to present consumption. An amount of \$AUD 11264.5 per annum could be saved by the university on utility bills for electrical appliances based on an average price of electricity of $0.114592 \mathrm{c} / \mathrm{kWh}$.
\end{abstract}

Keywords: Cost; survey; energy savings; energy wastage; electrical appliances.

\section{INTRODUCTION}

The aim of this study is to examine the energy consumption of the Playford building based on past data. Recommendations and possible methods that could be implemented in order to help reduce electricity usage in this building were outlined in this paper. An estimation of the amount that could be saved by the identified methods of energy reduction has been calculated and presented in order to indicate the impact to the cost incurred. The Playford $(P)$ building is located at the city east campus of the University of South Australia (UniSA) in Adelaide (Figure 1). This building has been utilized as offices for lecturers and other personnel of UniSA's staff, as well as by the students for teaching and learning purposes. In addition, this building also has a lecture hall, computer pools, meeting rooms, laboratories, a prayer room, an international student room, and a gymnasium. Overall, it is a seven storey building equipped with facilities for education. Regarding electricity appliances, this building uses laboratory equipment and appliances, computers, printers and laptops, split air-conditioning systems, lighting for computer pools, offices, corridors and toilets, pantry electrical appliances, for 
instance, microwaves, and gymnasium appliances as well as beverage vending machines. Each level has the same area and the plant layout is not much different. The plant layout for level 1 is shown in Figure 2.

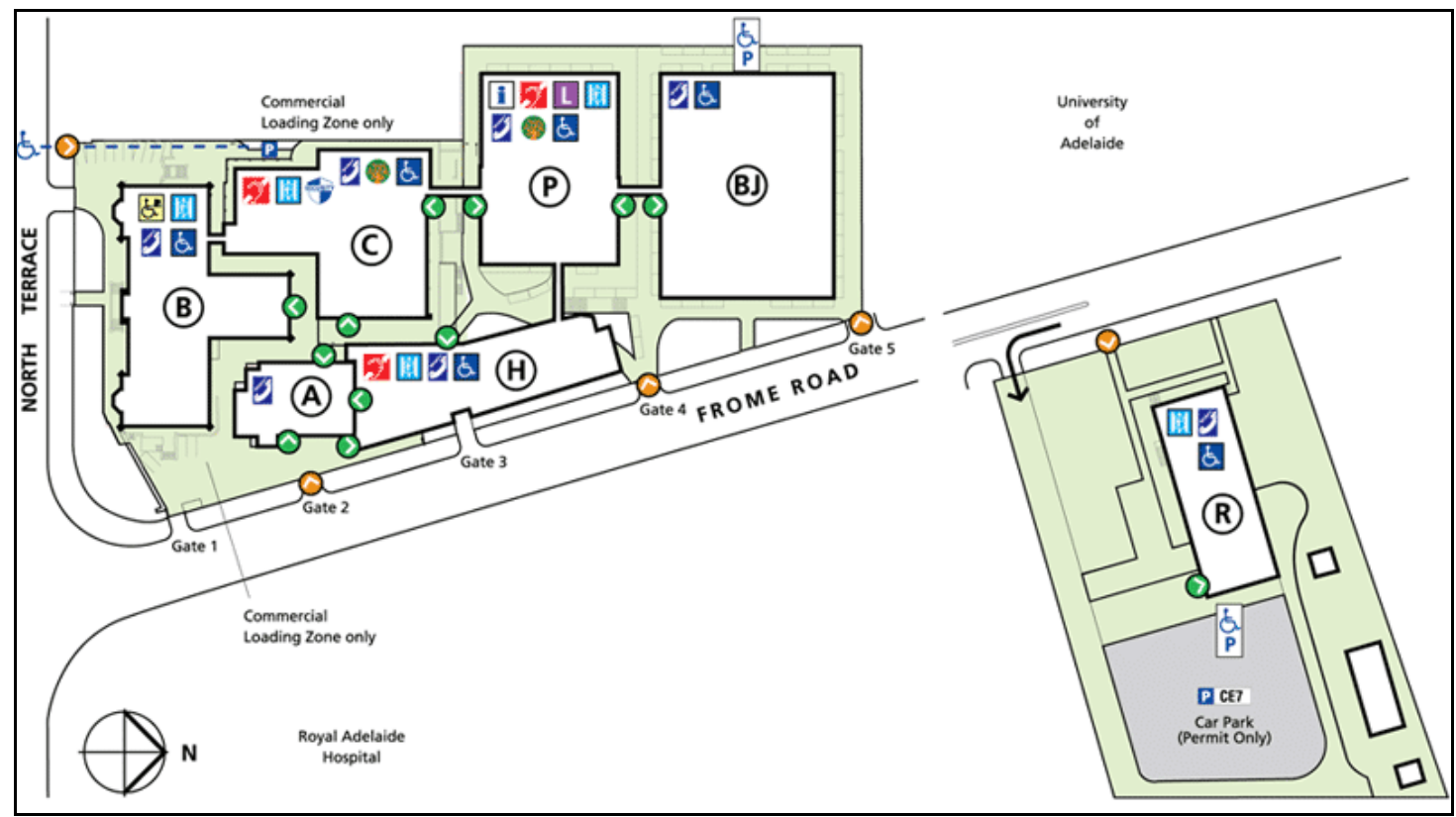

Figure 1. Location of playford building at city east campus, UniSA.

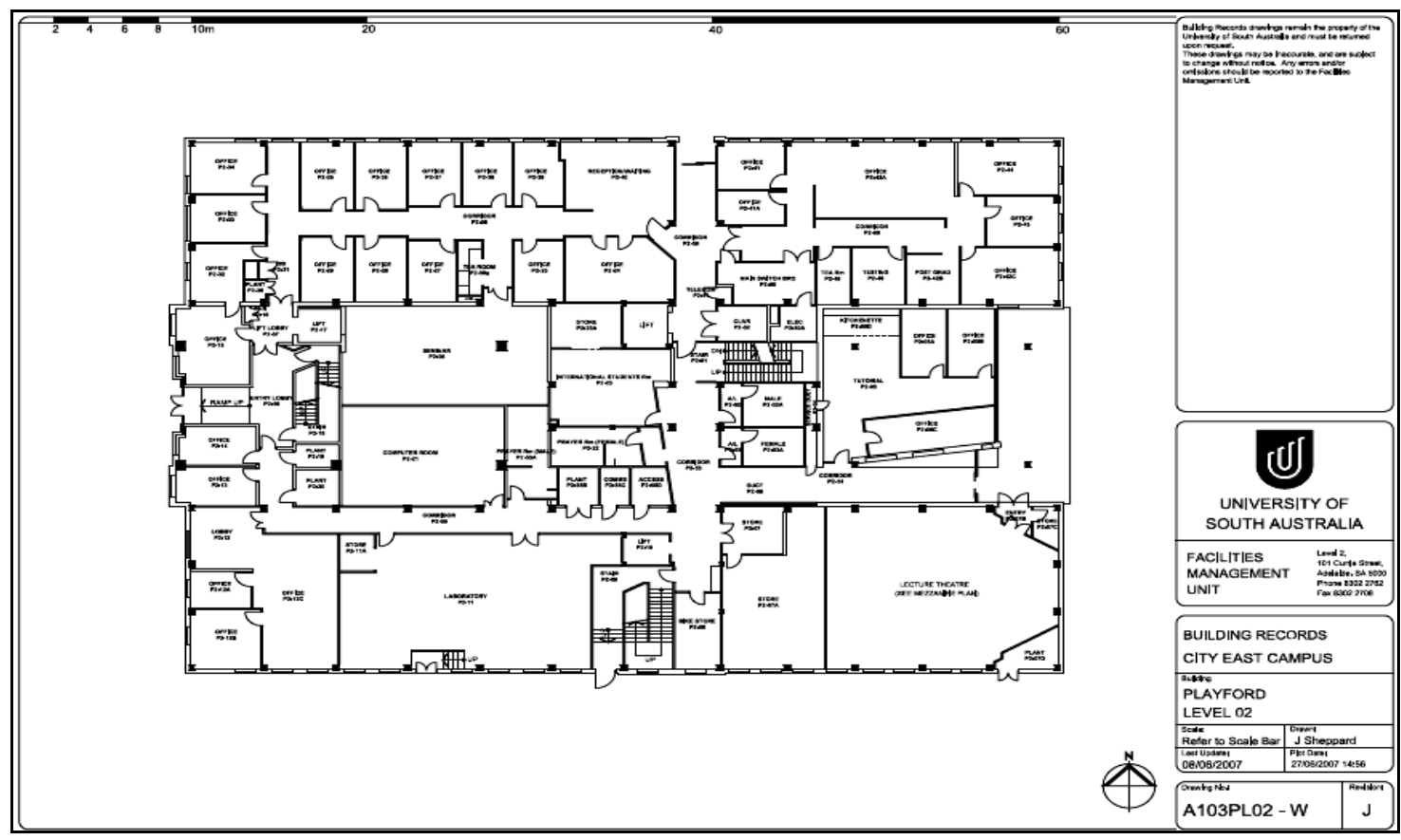

Figure 2. Plant layout for level 1 of playford building.

\section{METHODOLOGY}

The workflow of the audit is based on three phases of activity (Australian Government Publishing Service, 1994). Each phase is described as follows: 
Phase 1: An audit of historical data. This is being done by collecting past data of energy used. This phase will determine:

- $\quad$ The quantity of energy used.

- $\quad$ Annual seasonal pattern of energy consumed and its cost.

Phase 2: The screening survey. The screening study is necessary in order to indicate:

- $\quad$ Major energy-consuming appliances, equipment or systems.

- $\quad$ Obvious energy waste and inefficiencies.

- Priority areas for further investigation of inefficient or inappropriate energy systems.

Phase 3: Detailed investigation and data analysis. In this phase, an analysis on what was identified in phase 2 was carried out, in order to investigate and find ways to reduce energy wastage.

- Any systems or appliances identified in the screening survey were justified for further investigation to determine avoidable energy losses and the cost of reducing the waste.

\section{Phase 1: An Audit of Historical Data}

This energy audit survey focused only on electrical energy. In general, the total electricity consumption for the entire campus of UniSA was $25.9 \mathrm{GWh}$ at a cost of \$AUD 3,083,297 for the year 2008 (Martin, Lewis, Bruno, Saman, Marshall \& Jones, 2009a). Figure 3 shows the annual electricity consumption at UniSA from 2000 to 2007. The pattern of consumption shows an incremental increase starting in 2004 as the numbers of students increased year after year. The building occupied by the greater number of personnel contributes to increase the value. From Figure 3, in 2007, total energy consumption was over $25,000,000 \mathrm{kWh}$ with the off peak contribution increasing up to approximately $10,000,000 \mathrm{kWh}$.

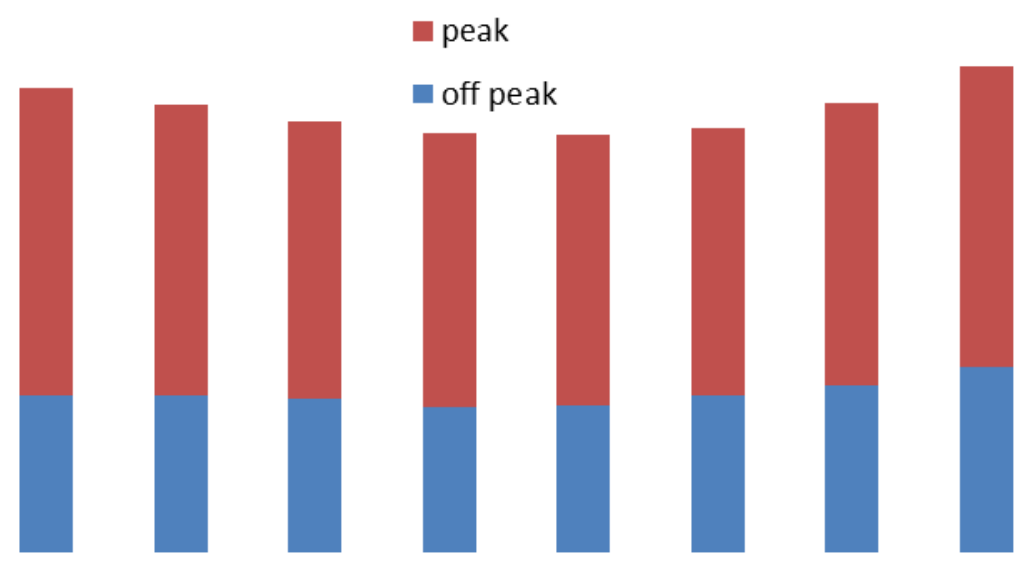

Figure 3. The annual electricity consumption at UniSA from 2000 to 2007

(Martin et al., 2009a). 
Reviewing Purchasing Arrangements: In general, there are many gas and electricity suppliers in South Australia, for instance, Australian Gas and Lights (AGL), Origin Energy, Energy Australia, TRU Energy, Aurora Energy, Australian Power and Gas, Horizon Power, Integral Energy, Power Direct, and others. However, UniSA has an agreement with AGL for a four-year contract for electricity supply. The consumption charge under this agreement is $14.7827 \mathrm{c} / \mathrm{kWh}$ during peak hours and $8.1357 \mathrm{c} / \mathrm{kWh}$ during off peak hours (Martin, Lewis, Bruno, 2009b).

Detailed Breakdown: For the Playford building, lighting, air conditioners and computers are the major contributors to expenditure on energy. During the walk-through survey, it was observed that these three items are the most used appliances in the building. They are used by students, lecturers and other staff while undertaking their work. Table 1 shows the University's inventory of total greenhouse gas emissions for 2007. From Table 1, it can be seen that electricity was the largest source of the University's emissions at $51 \%$ or 23108 ton of $\mathrm{Co}_{2}$-e due to delivered electricity.

Table 1. Carbon dioxide equivalent emissions by source at the University of South Australia (Martin et al., 2009a).

\begin{tabular}{clcc}
\hline \multirow{2}{*}{ Scope } & Source & $\begin{array}{c}\text { Emissions } \mathrm{CO}_{2}-\mathrm{e} \\
\text { (ton) }\end{array}$ & $\begin{array}{c}\text { Percentage of } \\
\text { total }\end{array}$ \\
\hline \multirow{2}{*}{1} & Gas combustion & 1021 & $2.3 \%$ \\
& Transport fuels & 539 & $1.2 \%$ \\
& Solid waste to landfill & 920 & 2.0 \\
& Fugitive hydrofluorocarbons & 1260 & $2.8 \%$ \\
& Total & 3,741 & $8.2 \%$ \\
\hline 2 & Electricity & 23108 & $51 \%$ \\
\hline \multirow{2}{*}{3} & Transmission loss (elect, gas \& & 4,280 & $9.4 \%$ \\
& fuel) & 536 & $1.2 \%$ \\
& Waste water treatment & 6,764 & $15 \%$ \\
& Transport (students) & 6,915 & $15 \%$ \\
& Transport (air travel) & 18,495 & $41 \%$ \\
\hline & Total & 45,343 & $100 \%$ \\
\hline
\end{tabular}

\section{Phase 2: The Screening Survey}

The next stage in this energy audit study involved a walk-through audit and occupancy survey. The purpose of this stage is to study the behavior of occupants and to survey what improvements could be made in identified areas in order to reduce energy wastage. In addition, all computers were checked whether energy-saving features had been enabled or not. This study provides initial ideas for improving the existing system. In this survey, the number of lights available and wattage for each level has been collected. The data regarding the energy-saving features of computers were also recorded.

Lighting: Lighting can be categorized as the most important electrical appliances used in any building. For the Playford building, lamps are vital because teaching and learning processes require adequate lighting to be provided. Figures 4 and 5 show the typical examples of the lights in the corridors and lecture halls. According to Martin et al. 
(2009b), total energy used for interior lighting was calculated to be approximately 6100 $\mathrm{MWh} /$ year or $24 \%$ of the total electrical energy consumed by the entire university. There are a few types of lights used in the Playford building on levels 2 and 3, for instance, fluorescent lamp tubes T8 and T5, halogen, and emergency lights. There are a number of different powered lights used in this building: 10, 25, 29, 45, and $50 \mathrm{~W}$. Basically, levels 2 and 3 both use the same sort of lights, but differences occur when there are different layouts, which require a different number of lights at each level. From the walk-through survey, it has been identified that the energy wasted owing to lights was because of:

i. Excessive lamp power. Based on Australian Standards for interior lighting AS 1680.2.1 (Australian Standard for Lighting, 2008), if an area has light power greater than $15 \mathrm{~W} / \mathrm{m}^{2}$, it is probably more than is required.

ii. The use of inefficient T8 fluorescent tubes, which use more power compared with T5 tubes (Elliot, 2008).

iii. The use of halogen lamps, which consume more power.

iv. Lights left $\mathrm{ON}$ in unoccupied rooms, especially offices and lecture rooms.

v. Excessive lighting in a room occupied by only a few staff or students at any one time, especially in the computer pools.

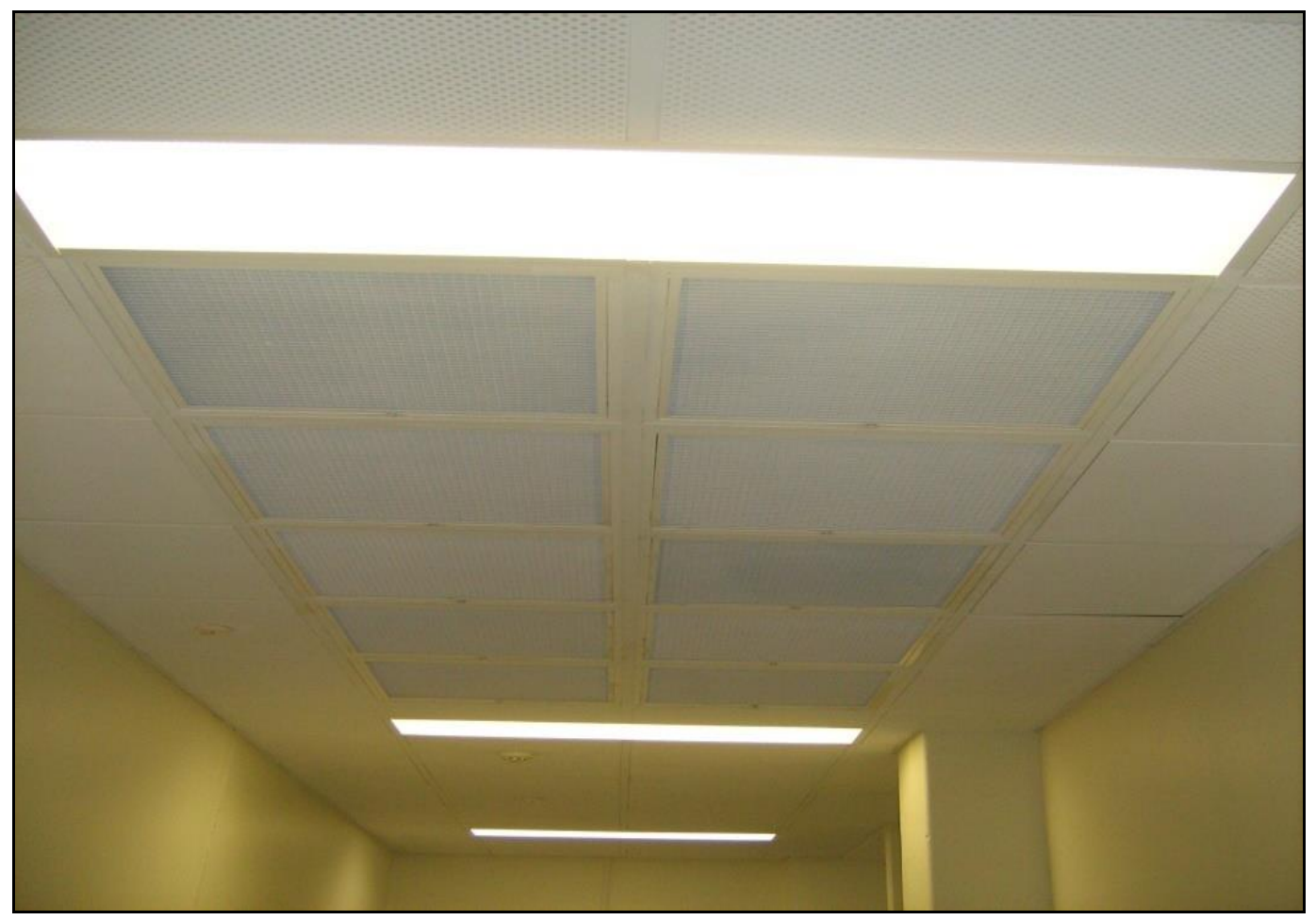

Figure 4. Lamps in corridor.

From the survey, it has been identified that each office on level 2 uses four units of fluorescent T8 lamps. The number and type of lights on level 2 have been counted and are presented in Table 2. On the other hand, it has been found that each office on level 3 also uses four units of fluorescent T8 lamps. The number and type of lights on level 3 have been counted and the results are also presented in Table 2. 
Table 2. Number of lamps on levels 2 and 3.

\begin{tabular}{ccc}
\hline \multirow{2}{*}{ Type of lamp (power) } & \multicolumn{2}{c}{ Total No. of Lamps } \\
\cline { 2 - 3 } & Level 2 & Level 3 \\
\hline 10 W & 17 & 9 \\
$25 \mathrm{~W}$ & 22 & 134 \\
$29 \mathrm{~W}$ & 59 & 32 \\
$36 \mathrm{~W}$ & 300 & 347 \\
$45 \mathrm{~W}$ & 13 & 13 \\
$50 \mathrm{~W}$ & 8 & 6 \\
\hline
\end{tabular}

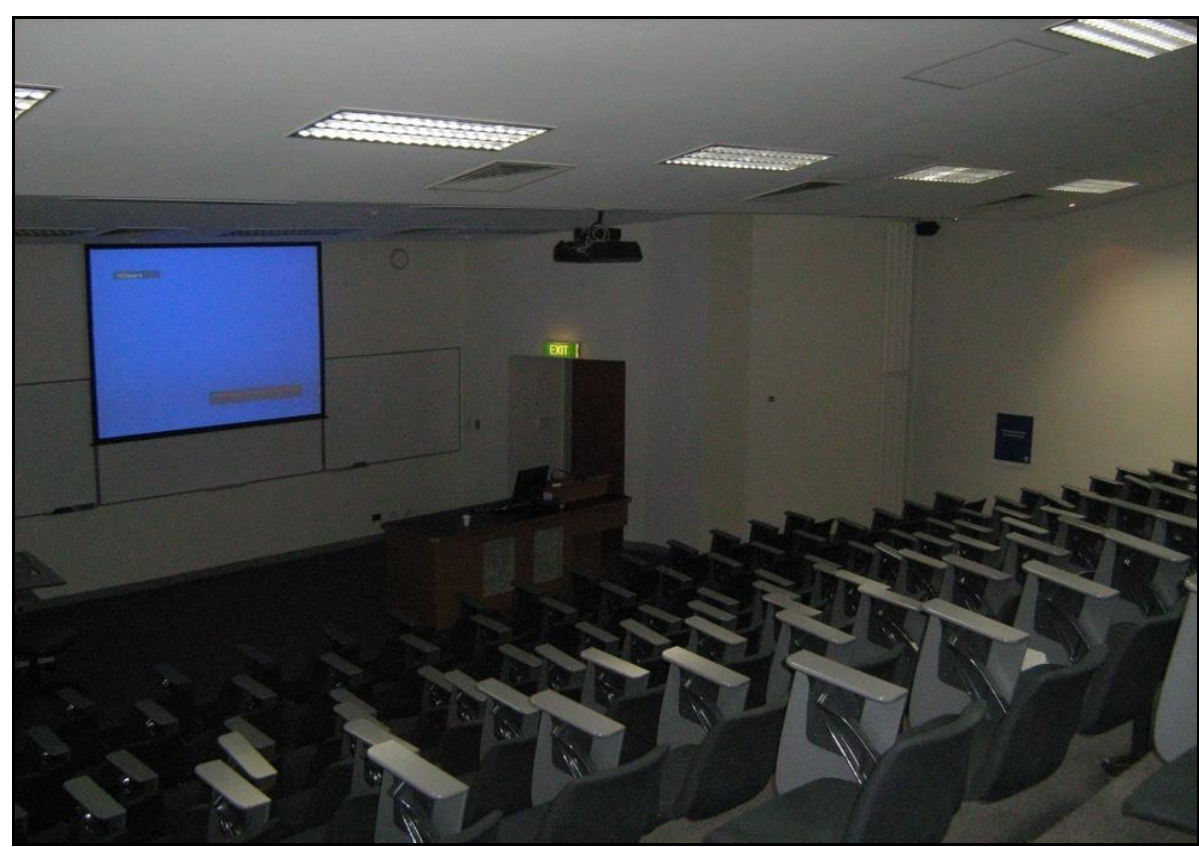

Figure 5. Lamps in the lecture hall.

Table 3. Energy management options enabled on computers.

\begin{tabular}{llclc}
\hline \multirow{2}{*}{ Room No. } & \multicolumn{2}{c}{ Computer 1 } & \multicolumn{2}{c}{ Computer 2 } \\
\cline { 2 - 5 } & Monitor OFF & Standby Mode & Monitor OFF & $\begin{array}{c}\text { Standby } \\
\text { Mode }\end{array}$ \\
\hline P221 & After 2 hours & Never & After 2 hours & Never \\
P318 & After 1 hour & Never & After 1 hour & Never \\
P319 & After 20 mins & Never & After 20 mins & Never \\
P321 & After 2 hours & Never & After 2 hours & Never \\
P333 & After 2 hours & Never & After 2 hours & Never \\
P334 & After 2 hours & Never & After 2 hours & Never \\
P335 & After 1 hour & Never & After 1 hour & Never \\
P338 & After 20 mins & Never & After 20 mins & Never \\
\hline Average & After 80 mins & Never & After 80 mins & Never \\
\hline
\end{tabular}

Computers: Figure 6 shows the computers in the computer pool. During the survey, it was checked whether the computers in the computer pools had energy-saving features 
enabled on the computer or not. The procedure of checking was by observing the following sequence: "Start/Settings/Control Panel/Power Options". Two computers were checked and taken as representative of all the computers in a computer pool. The results are displayed in Table 3.

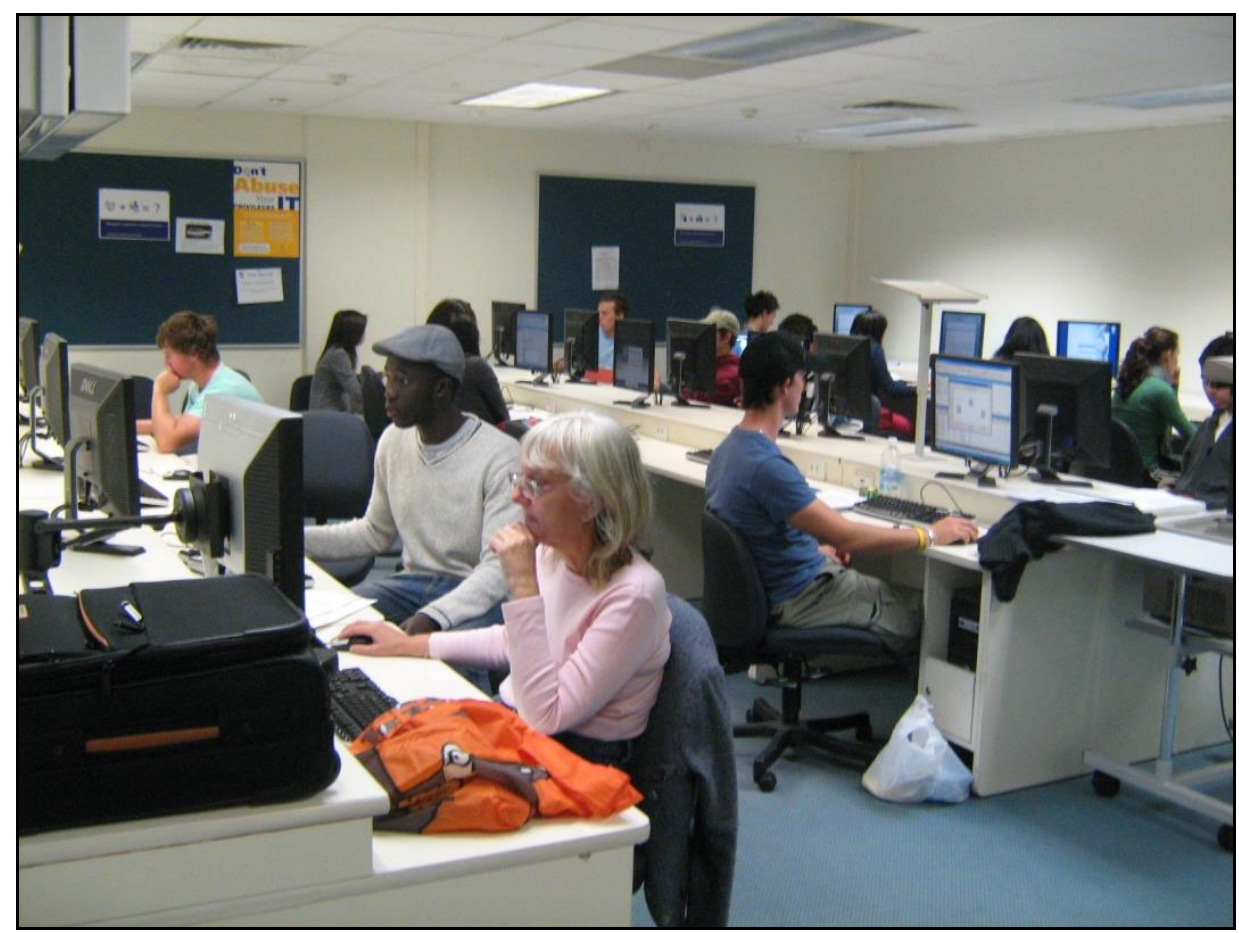

Figure 6. Computers in the computer pool.

Air-conditioning: According to Martin et al. (2009b), there are three chillers at the Playford building, each of which has different capability and age. Two of them use reciprocating compressors, which are known to be an older technology and less efficient than current generation compressors, important factors should replacements be considered. On the other hand, heating is provided by three boilers at the Playford building. Two of them were working properly in one plant room, whereas the other one is being repaired. However, for the sake of efficiency, the boiler under repair should be replaced because it is old. From the walk-through survey, it has been identified that the waste of energy due to the air-conditioning includes:

i. Room has been left with air conditioner still ON because the room is equipped with a push button air conditioner.

ii. Infiltration load due to sliding door at many entrances to levels 2 and 3 in the Playford building.

iii. Room with push button air conditioner has been left with door open, which causes extra workload for the air conditioner to maintain the required temperature.

Infiltration Load: Identified infiltration is due to the outside air coming inside, and vice versa. This requires the air conditioner to work harder in order to maintain the specified temperature; hence, more energy is consumed. 


\section{RESULTS AND DISCUSSION}

In this phase, the data collected in the screening survey were analyzed. Thorough investigations towards the effort of energy reduction were undertaken and recommendations outlined. The recommendations made are focused on the anticipated energy reduction targets. Comparisons of calculations were made between existing usage and that under the proposed plan. However, only one example of the calculation is shown in this paper.

Lighting: Push button timers for lighting are used widely at UniSA, especially for computer pools and lecture rooms. This is to control lighting and to avoid unused light when the room is left unoccupied. Hence, this recommendation cannot be made for the Playford building because it is already in use. However, it is possible should occupancy sensors be fixed in the toilet and on the staircase. In this phase, all calculations for the lighting costs are made with some assumptions. These assumptions are considered in order not to bias the results for the calculations between the present condition and the proposed plan. The value of the calculation will show the difference between both of the conditions and the assumptions made in order to achieve the lowest cost. The assumptions include:

i. The lights are ON for 24 hours for lighting the corridors, toilet, staircase, and emergency lights. Other lights are assumed used for 12 hours per day from 9.00 am to $9.00 \mathrm{pm}$.

ii. Lights in offices are $\mathrm{ON}$ for 12 hours per day.

iii. Computers are $\mathrm{ON}$ for 12 hours during the peak hours, starting from 9.00 am to $9.00 \mathrm{pm}$, because the high number of users.

iv. There are only 26 working days per month for the electrical appliances to be used.

Energy Savings by the Application of Occupancy Sensors: In total, there are 26 lamps used in 4 toilets and on 2 staircases on levels 2 and 3 of the Playford building. The toilets have four doors and the staircases also have four doors for both levels. Occupancy sensors could be fixed in front of the doors, such that they detect the presence of human beings as soon as they open the doors to enter the toilets or staircases. Occupancy sensors are suitable for the toilets and staircases because these areas have users coming and going all the time. The tariff used for the calculation here is assumed an average value between the peak and off peak hours, which is $11.4592 \mathrm{c} / \mathrm{kWh}$. The estimated energy savings calculation is shown as follows.

\section{Cost of energy consumption for toilets and staircases without sensor (existing condition)}

$\begin{array}{ll}\text { Total number of lamps } & =26 \text { lamps }(45 \mathrm{~W}) \\ \text { Total watts } & =26 \times 45 \mathrm{~W} \\ & =1170 \mathrm{~W} \\ & =\text { Total watts } \times \text { running hours } / \text { month } \times 12 \text { months/year } \\ & =1170 \mathrm{~W} \times 24 \text { hours } \times 26 \text { days } \times 12 \text { months/year } \\ & =8760960 \text { watts } / \text { year } \\ \text { Annual cost } & =\text { Annual usage }(\mathrm{kW}) \times \mathrm{kWh} \text { price }\end{array}$




$$
\begin{aligned}
& =(8760960 / 1000) \times 0.114592 \\
& =\$ \text { AUD 1003.94/year }
\end{aligned}
$$

As the toilets and staircases lighting will be unused during off peak hours, the application of occupancy sensors will make the lights OFF for at least 12 hours (minimum) per day starting from $9.00 \mathrm{pm}$ to $9.00 \mathrm{am}$. The calculation for this approach is as shown below.

\section{Cost of energy consumption for toilets and staircases with sensor (proposed plan)}

$\begin{array}{ll}\text { Total number of lamps } & =26 \text { lamps }(45 \mathrm{~W}) \\ \text { Total watts } & =26 \times 45 \mathrm{~W} \\ & =1170 \mathrm{~W} \\ & =\text { Total watts } \times \text { running hours/month } \times 12 \text { months/year } \\ & =1170 \mathrm{~W} \times 12 \text { hours } \times 26 \text { days } \times 12 \text { months/year } \\ & =4380480 \text { watts } / \text { year } \\ & =\text { Annual usage }(\mathrm{kW}) \times \mathrm{kWh} \text { price } \\ & =(4380480 / 1000) \times 0.114592 \\ & =\$ A U D 501.99 / \text { year } \\ & =\text { Existing cost }- \text { Proposed plan cost } \\ & =\$ A U D 1003.94-\$ \text { AUD } 501.99 \\ \text { Total savings/year } & =\text { AUD } \$ 501.95 / \text { year }\end{array}$

\section{Payback Period}

The cost for one sensor is about \$AUD 170. As there are eight doors involved for all the toilets and staircases, the cost should be multiplied by eight.

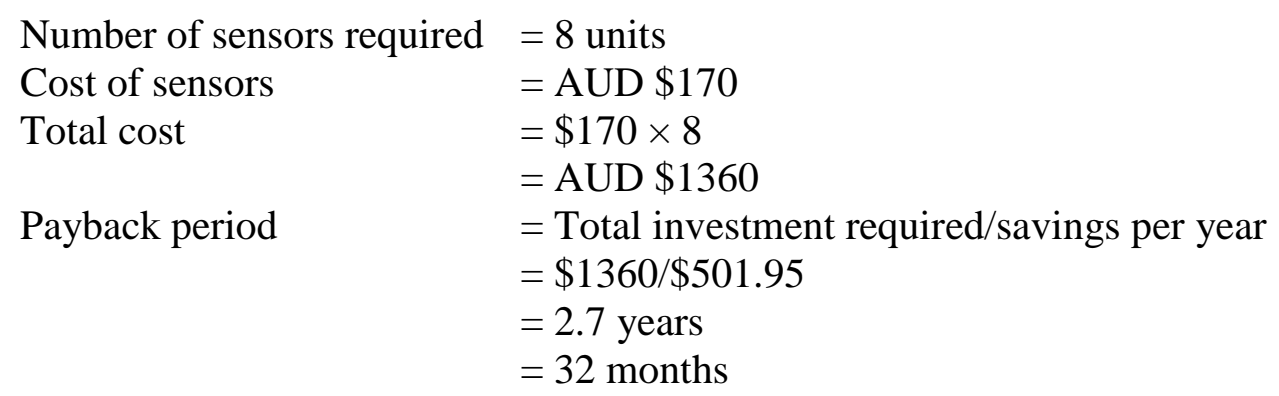

Reduction of the Number of Lights in Specified Areas: During the walk-through audit, it was identified that offices and tea rooms are areas that utilize excessive lighting, where it should not more than $15 \mathrm{~W} / \mathrm{m}^{2}$ (Australian Standard for Lighting, 2008). This was identified by a simple calculation involving the number of lights used multiplied by the total wattage, divided by the area of that room. Hence, these two areas could contribute to the reduction of energy consumption. There are 132 lights through 31 offices and 2 tea rooms on levels 2 and 3. Each room uses four lights. It is recommended that each room be equipped with just three lights. This action is deemed adequate to provide sufficient light for the entire area of each room. The calculation for the energy savings in this approach is the same as that shown for the energy savings by applying sensors in the previous section. 
Change Fluorescent Tubes from T8 to T5: According to Elliot (2008) and Martin et al. (2009a), the T8 tube consumes more power owing to inductive ballast. A $36 \mathrm{~W}$ T8 tube actually consumes up to $45 \mathrm{~W}$ of power because of $9 \mathrm{~W}$ of inductive ballast, whereas a $28 \mathrm{~W}$ T5 tube consumes up to $30 \mathrm{~W}$ ( $2 \mathrm{~W}$ inductive ballast). The light produced by both tubes is the same. In total, 647 units of T8 fluorescent tubes are used for both levels 2 and 3 with 12 hours consumption per day. However, if the lights in the staff offices were reduced from 4 to 3 units, the total number of lights will be reduced to 614 units.

Change Halogen Lights from $50 \mathrm{~W}$ to $35 \mathrm{~W}$ : Overall, there are seven units of halogen $50 \mathrm{~W}$ lights on both levels 2 and 3. Six of them are located in the toilets and another one in the lecture hall. It is recommended to replace these lights with the same pattern of 35 W lights, which have the same fitting. These types of light produce the same quantity of light, but consume less power.

\section{Computers:}

For the computer analysis, this part is separated into two sections: computers in the computer pools, and computers in office.

Computers in the Computer Pools: Computers in the computer pools were analyzed in terms of their energy-saving features. Computers in the staff offices will not be considered in this analysis because it is difficult to check their energy-saving features owing to the requirement of obtaining permission from the room's occupant. In total, for both levels 2 and 3, there are 178 computers in eight computer pools. The results for the energy-saving features are presented in Table 3. Based on the walk-through survey, it was found that the average time for a computer to turn into standby mode was 80 minutes. This is based on the setup of the energy-saving features. Instead of a limit of 80 minutes, it is recommended that a 20 -minute limit be implemented for the energysaving features of all 178 computers. It is estimated that one computer will consume 50 watts of energy per hour when ON with the monitor in standby mode. For this analysis, other assumptions have to be made, including:

i. All 178 computers in the computer pools are used concurrently and are unused at the same time.

ii. All 178 computers are left for a maximum of only one time per day.

iii. It is estimated that only 50 watts of energy pre hour are consumed when the computers are $\mathrm{ON}$, but with the monitor in standby mode.

This analysis will examine how much energy could be saved during standby mode for durations of 20 and 80 minutes.

Computers in the Office: For computers in the office, it is highly recommended that the computer be replaced by a laptop. For the sake of energy savings, a laptop is deemed certain to be turned OFF during off peak hours, unlike the existing computers. Despite this recommendation requiring a high level of investment, it is practically viable to be implemented. 


\section{Air-Conditioning}

During the survey, all rooms were found equipped with push button switches. It is highly recommended that timer control units be used instead of push button switches. Once the push button has been pressed to start the system, users normally leave the room without re-pressing the button to stop it. To analyze the amount that could be saved by using a timer control unit, it is assumed that the air conditioner in each room operates for 12 hours during the peak hours. This is based on the assumption that having pressed the push button to start the system, they will not re-press the button to turn it off again. By using a timer control unit, it is assumed that air conditioners in rooms will operate for only 10 hours per day (minimum). Thus, two hours' use will be saved when the room is unoccupied. This is the result of the implementation of a timer control unit. Power consumed by the air conditioner is $3 \mathrm{kWh}$. Across 31 offices and 1 lecture hall for both levels 2 and 3, the timer will be set at 2 hours for every single pressing. The price of the timer control unit is estimated at approximately \$AUD 100 per unit.

\section{CONCLUSION}

The summary of energy cost saving is summarized in Table 4. The total cost of the implementation of the proposed plan and the total saving per year are also displayed in that table. It can be seen from Table 4 that the total saving that could be achieved is \$AUD 11420.24 per annum. The calculation of the overall payback period is shown below.

Overall payback period = Total investment required/Savings per annum

$$
\begin{aligned}
& =\$ 9813 / \$ 11420.24 \\
& =0.9 \text { years } \\
& =11 \text { months }
\end{aligned}
$$

In short, for the six proposed plans, the implementation of two of them will cost nothing. Delamping and computer energy-saving features will have zero cost because these two proposed plans just require a reduction of the existing systems and not an upgrade as with the other four plans. Overall, the university will achieve payback for the investment of all these proposed plans in 11 months. This excludes the small fixing cost and maintenance cost. On average, the university could save up to $20.4 \%$ a year on its utility bills if the proposed plan for the Playford building were implemented.

Percentage of savings $=\frac{\text { Saving per year }}{\text { Existing cost per y ear }} \times 100 \%=\frac{11264.5}{55296.34} \times 100 \%=20.4 \%$ 
Table 4. Summary of energy cost savings through proposed plans.

\begin{tabular}{lcccc}
\hline Proposed plan & $\begin{array}{l}\text { Existing cost } \\
\text { expenses } \\
\text { (\$AUD/year) }\end{array}$ & $\begin{array}{l}\text { Proposed cost } \\
\text { expenses } \\
\text { (\$AUD/year) }\end{array}$ & $\begin{array}{l}\text { Cost } \\
\text { involved } \\
\text { (\$AUD/year) }\end{array}$ & $\begin{array}{l}\text { Savings }(\$ \\
\text { AUD/year) }\end{array}$ \\
\hline $\begin{array}{l}\text { 1. Occupancy sensor } \\
\text { 2. Delamping }\end{array}$ & 1003.94 & 501.99 & 1360 & 501.95 \\
$\begin{array}{l}\text { 3. Change of T8 to T5 } \\
\text { Change of halogen }\end{array}$ & 9448.45 & 1911.34 & 0 & 637.11 \\
$\begin{array}{l}\text { 50 W to 35 W } \\
\text { Computers energy- } \\
\text { saving features }\end{array}$ & 150.16 & 6585.65 & 4912 & 2897.68 \\
$\begin{array}{l}\text { Air conditioner timer } \\
\text { control switch }\end{array}$ & 413.66 & 95.46 & 77 & 45.05 \\
\hline Total & 54706.65 & 43522.15 & 0 & 318.20 \\
\hline
\end{tabular}

\section{REFERENCES}

Australian Government Publishing Service. (1994). The Energy Audit.

Australian/New Zealand Standard (AS/NZS). (2008). Interior and Workplace Lighting, 1680.2.1.

Elliott, R. (2008). Traditional fluorescent tube lamps \& their alternatives. Retrieved from http://sound.westhost.com/lamps/fluorescent.html>

Engineering Systems (India) Pvt Ltd. (2009). Power Savings and ROI by use of LED Lighting technology for Cove lighting applications compared to conventional T5 tube lights.

Martin, S. O., Lewis, A., Bruno, F., Saman, W., Marshall, A., \& Jones, T. (2009a). Reduction of greenhouse emissions from the University of South Australia Learning to Educate with Less.

Martin, S.O. Lewis, T., \& Bruno, F. (2009b). University of South Australia Energy Audit. 